\title{
Control of Offshore Wind Turbines Connected to Diode-Rectifier-Based HVdc Systems
}

\author{
Bidadfar, Ali; Saborío-Romano, Oscar; Cutululis, Nicolaos A.; Sørensen, Poul E.
}

Published in:

IEEE Transactions on Sustainable Energy

Link to article, DOI:

10.1109/TSTE.2020.3008606

Publication date:

2021

Document Version

Peer reviewed version

Link back to DTU Orbit

Citation (APA):

Bidadfar, A., Saborío-Romano, O., Cutululis, N. A., \& Sørensen, P. E. (2021). Control of Offshore Wind Turbines Connected to Diode-Rectifier-Based HVdc Systems. IEEE Transactions on Sustainable Energy, 12(1), 514-523. https://doi.org/10.1109/TSTE.2020.3008606

\section{General rights}

Copyright and moral rights for the publications made accessible in the public portal are retained by the authors and/or other copyright owners and it is a condition of accessing publications that users recognise and abide by the legal requirements associated with these rights.

- Users may download and print one copy of any publication from the public portal for the purpose of private study or research.

- You may not further distribute the material or use it for any profit-making activity or commercial gain

- You may freely distribute the URL identifying the publication in the public portal 


\title{
Control of Offshore Wind Turbines Connected to Diode-Rectifier-Based HVdc Systems
}

\author{
Ali Bidadfar ${ }^{\mathbb{D}}$, Oscar Saborío-Romano ${ }^{\mathbb{D}}$, Nicolaos A. Cutululis ${ }^{(\mathbb{D})}$, Poul E. Sørensen ${ }^{(\mathbb{D}}$
}

\begin{abstract}
Diode-rectifier-based high voltage dc (DR-HVdc) systems can be a promising low-cost solution for exporting wind power from remote offshore wind farms to onshore power systems. Industrializing the offshore DR-HVdc requires technical maturation, achievable through in-depth studies and pilot experiments. Deployment of offshore DR-HVdc systems may entail a fundamental change of control philosophy in wind turbine (WT) converters from grid-following control to gridforming. This paper proposes a new grid-forming control for DRconnected offshore WT converters. The proposed controller uses two sequential control loops to regulate WTs' active power, and maintain the frequency and voltage of the offshore ac network. The first control regulates the active-power mismatch of each WT into a voltage angle deviation, which leads to a frequency change. The second control adjusts the WT's alternating voltage magnitude to counteract the frequency change. An internal current control loop is used to limit the fault current and eliminate high-frequency resonances in the system. The proposed control is verified by electromagnetic transient simulations, including faultride through, WTs power change, reactive power disturbance, and WTs outage.
\end{abstract}

Index Terms-Offshore wind farms, diode rectifiers, HVDC, converter control.

\section{INTRODUCTION}

O FFSHORE wind installation is proliferating worldwide. Europe's cumulative offshore wind capacity reached 18.499 MW at the end of 2018 [1]. Further increase in offshore wind power, various developments are focused on its generation and transmission systems. High-voltage ac links are predominantly used in offshore transmission [2]. However, the use of the ac links is limited to the offshore wind farms (OWFs) located relatively close to the shore (less than around $80 \mathrm{~km}$, if not compensated at the middle). For remote OWFs, the high voltage $\mathrm{dc}(\mathrm{HVdc})$ power transmission system is a cost-effective solution. To date, the power conversion in offshore HVdc transmission has been based on the voltagesourced converters (VSCs), which provide technical advantages such as independent control of active and reactive power, current control, and grid-forming capability.

Diode-rectifier-based $\mathrm{HVdc}$ (DR-HVdc) has been received an interest in possibly being used as a transmission system for remote OWFs [3]-[8]. Compared to the conventional VSC-based HVdc (VSC-HVdc), DR-HVdc can provide advantages such as smaller footprints in offshore platforms,

This work has received funding from the European Union's Horizon 2020 research and innovation program under grant agreement No 691714.

A. Bidadfar, O. Saborío-Romano, N. A. Cutululis, and P. E. Sørensen are with the Department of Wind Energy, Technical University of Denmark, Frederiksborgvej 399, 4000 Roskilde, Denmark (e-mail: abid@dtu.dk; osro@dtu.dk; niac@dtu.dk; posq@dtu.dk). higher efficiency, higher reliability (since it has less power electronic components) [9], and lower costs [7]. The main drawback of DR-HVdc, however, is the lack of grid-forming capability at its offshore ac terminals. Therefore, most of the proposed applications of such a transmission system rely on a fundamental change in the control philosophy of offshore WT converters, from grid-following to grid-forming units [3]. Such change in control philosophy is, however, one of the main obstacles for the industrialization of DR-HVdc technology.

For the first time, the grid-forming control was proposed in [3] for DR-connected WTs, maintaining the voltage and frequency in the farm with a centralized control scheme. This control scheme was further advanced to perform fault ridethrough [5], and have more satisfying harmonic mitigation, and hence, smaller filter size in the rectifier station [10]. Another type of grid-forming control was proposed in [11], using the global positioning system (GPS) to provide a synchronizing signal to WT converters. A distributed phase-locked loop (PLL) based frequency control was proposed in [8] as a decentralized control enabling each WT to operate as a gridforming converter without a need for communication links or GPS signal. This control method was improved to have better performance under faulty conditions [12], and was validated achieving frequency support to onshore power systems [13].

This paper proposes a new grid-forming control for DRconnected offshore WT converters. In the proposed control scheme, the active power change of each WT is initiated by regulating the voltage angle of the WT converters. The voltage angle change without proper regulation of voltage magnitude results in a frequency deviation, which is detected by all WT converters. Such deviation is then translated into a voltage magnitude change via a proportional-integral (PI) regulator in each WT converter. As a result, all WT converters change their voltage magnitude, synchronously. The synchronous change of voltage magnitude is the distinguishing feature of the proposed control from those in [3], [8], [11], it prevents the reactive power swing among WTs.

The control scheme includes inner-current control to limit the fault current and alleviate the system's high-frequency resonances. The proposed control benefits from:

- being relatively simple, having fewer control parameters to tune, compared to other controls proposed for DRconnected offshore WTs,

- enabling each WT to control its active power independently,

- being decentralized, requiring neither communication links nor GPS signal, and

- limiting fault current and mitigating system resonances. 


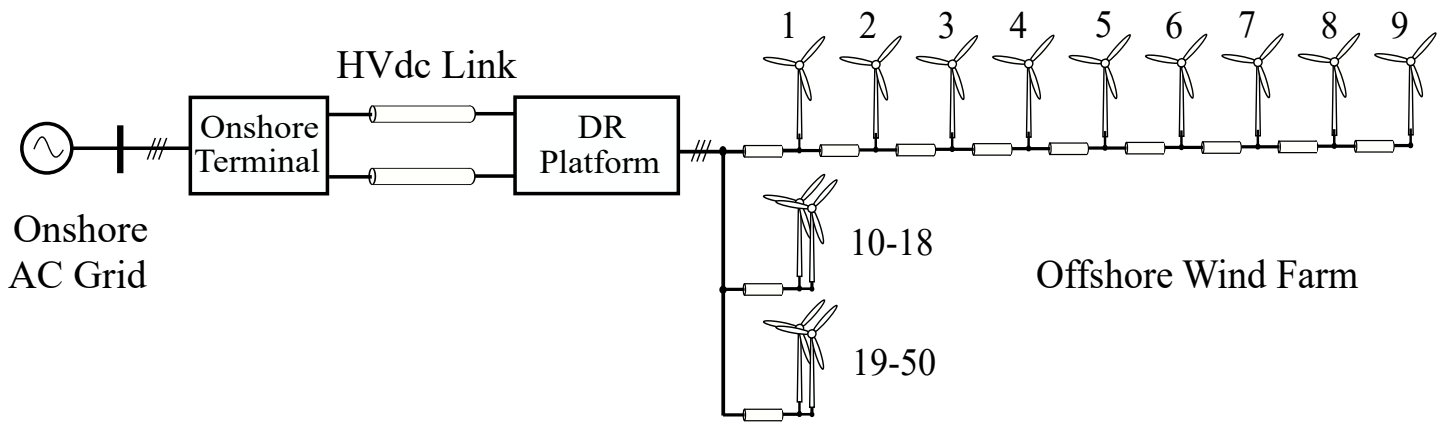

Fig. 1. A schematic diagram of an offshore wind power plant connected to HVdc via diode rectifier converters.

The rest of the paper is organized as follows. The models of offshore wind farm, DR platform and export system used for analyses and simulations are explained in Section II. The details of the proposed control approach are given in Section III. Section IV presents the simulation results and the paper is concluded in Section V. All control and system parameters used for simulations are provided in the Appendix.

\section{WIND FARM AND WIND TURBINE MODELS}

Figure 1 shows the schematic diagram of the studied system. The system is based on the model described in [13]-[15] and consists of a $400 \mathrm{MW}$ OWF connected to an onshore ac network by means of a monopolar DR-based HVdc link. The onshore ac network has been modeled as a grid with a short circuit level of $8000 \mathrm{MVA}$ and X/R ratio of 15 . The onshore HVdc terminal consists of VSCs, which control the voltage on their dc terminals and the reactive power injected into the onshore ac network.

The offshore HVdc terminal, labelled in Fig. 1 as "DR Platform", consists of two (uncontrolled, line-commutated) diode-based 12-pulse rectifiers (DRs) connected in series, with corresponding reactive power compensation and filter bank on their ac side [13].

The OWF has 50 WTs with $8 \mathrm{MW}$ nominal production capacity. The WTs use fully-rated (type-4) power electronic converters connecting to offshore ac grid. The WTs are laid out in 6 strings in the OWF. The first string, comprised of WTs 1-9 is represented in detail. The second string, consisting of WTs $10-18$, is aggregated into an equivalent $72 \mathrm{MW}$ WT and corresponding cable equivalent $\pi$ circuit using the method proposed in [16]. Likewise, the other 4 strings, comprising WTs 19-50, are aggregated into an equivalent $256 \mathrm{MW}$ WT and corresponding cable equivalent $\pi$ circuit.

For computational efficiency, dynamics in each WT dc link and behind it are not considered, and the VSCs' direct voltage is thus assumed constant (ideally regulated by the back-end/ machine-side converter) as justified in [3], [4], [8]. Pulse-width modulation (PWM) is assumed to be implemented within a linear range. Switching effects and any delay due to PWM implementation are taken into account as explained in the next Section. The average-value models are used to represent all WT converters.

The schematic diagram of a WT's grid-side converter is shown in Fig. 2. The ac components, phase reactor and filterbus capacitor, are indicated with $L_{\mathrm{c}}$ and $C_{\mathrm{f}}$, respectively. The

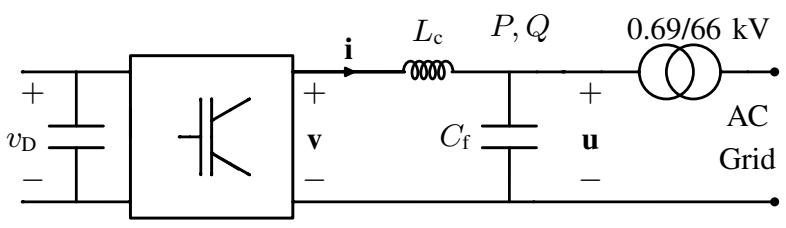

Fig. 2. Schematic diagram of a wind turbine's grid-side converter and its ac components.

three-phase electrical parameters (currents and voltages) are represented with bold letters. $\mathbf{v}$ is the converter's internal voltage vector, $\mathbf{i}$ is the converter current vector, and $\mathbf{u}$ is the filter-bus voltage vector. The main goal of the proposed control is to regulate the $\mathbf{v}$ such that WTs grid-side converters can control their active power, maintain the offshore frequency and establish reactive power balance in entire wind farm.

\section{Control Model Description}

\section{A. Control Requirements}

The grid-side converters of the WTs, connected to a DRconnected OWF, operate as grid-forming converters and are expected to meet some control requirements [8], such as WTs active and reactive power control, ac voltage and frequency of offshore ac grid control. To satisfy such requirements, this paper presents the control system, shown in Fig. 3 for these converters.

\section{B. Overview of the Proposed Control System}

Figure 3 shows the proposed control overview for the WTs' grid-side converters. The proposed control scheme has two main layers: an outer control and an inner control layer. The outer one consists of controllers for active power, reactive power, and offshore grid frequency. The outputs of these controllers are $\theta_{0}$ and $V_{0}$, which are respectively, the angle and magnitude of the initial reference vector, $v_{\mathrm{d} 0}+j v_{\mathrm{q} 0}$, of the converter's voltage $\mathbf{v}$.

In the inner control layer, the converter's current is controlled using the inputs from the outer control loop, and the system measurements, consisting of filter-bus voltage $\mathbf{u}$ and converter current $\mathbf{i}$. The output of this current control loop-eventually the output of the entire control system-is the final reference vector, $v_{\text {dref }}+j v_{\text {qref }}$, of the converter's voltage. 


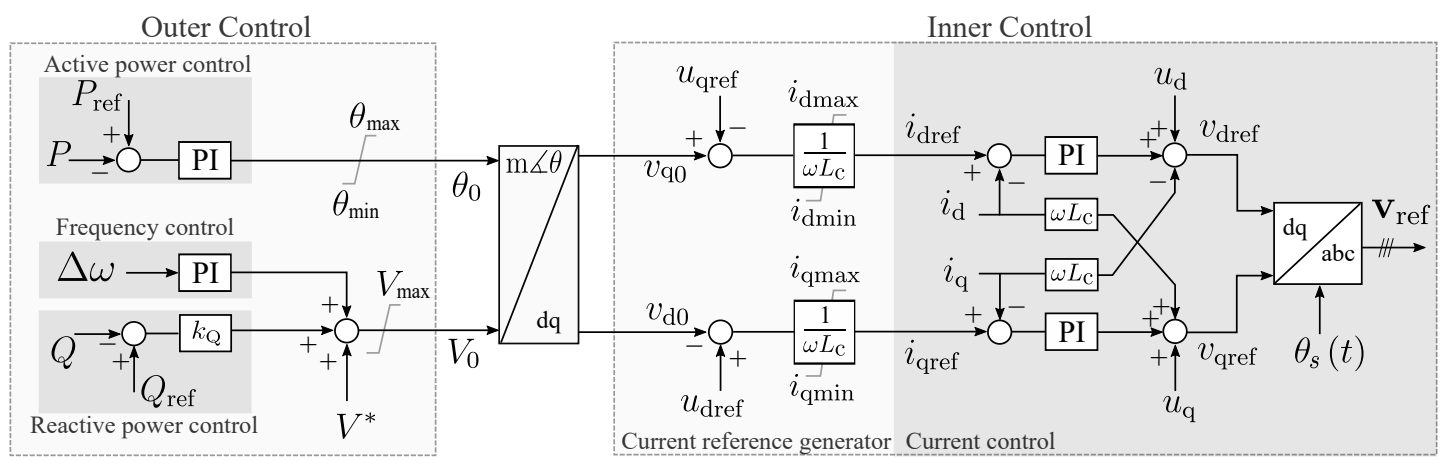

Fig. 3. Overview of the proposed control scheme for DR-connected grid-forming WT converters.

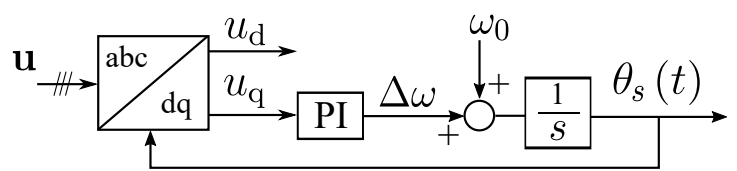

Fig. 4. Block diagram of the PLL used for dq-frame control and synchronization purpose of the DR-connected gridforming WT converters.

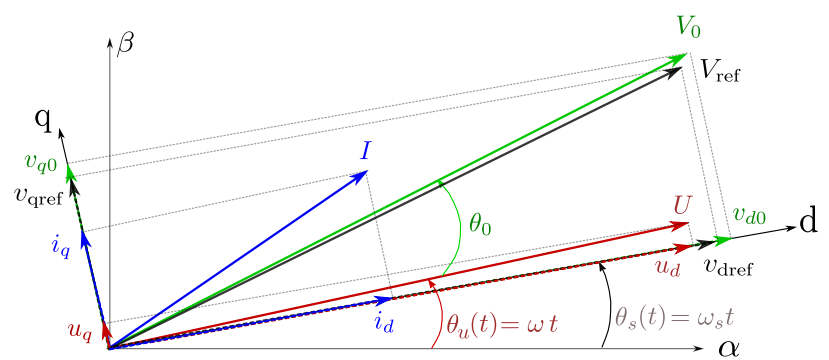

Fig. 5. Space vector diagram of voltage and current of a WT with the grid-forming control scheme shown in Fig. 3

The angle reference of all dq components of electrical parameters (currents and voltages) is generated by a phaselocked loop (PLL), shown in Fig. 4, synchronized to the filter-bus voltage $\mathbf{u}$. This PLL also estimates the frequency deviation, $\Delta \omega$, used in the outer layer of the proposed control, shown in Fig. 3.

\section{Outer Control Layer}

Similar to the power-angle control [17], [18], in the proposed control scheme, the active power $P$ is controlled by regulating the converter's voltage angle, $\theta_{0}$. However, since a DR-connected OWF is a passive network, increasing the voltage angle without providing enough voltage magnitude results in a frequency increase, without any change in the active power, flowing from ac to dc side of the DR converters. To establish the power flow through DR converters, while keeping the power-angle control concept, in the proposed control method, the frequency deviation is used to change the voltage magnitude, $V_{0}$, through a PI regulator to retain the offshore frequency to its nominal value. As a result, increasing voltage angle results in an increase of voltage magnitude, and consequently, an increase of active power.
In the outer control loop, a proportional controller is used to establish the wind farm's reactive power by WTs grid-side converters. To prevent significant reactive power-flow from WTs to the offshore substation in high active-power generation condition-to compensate the DR's low power factor-a passive reactive-power compensation has been included in the offshore substation. The $V^{*}$, in the proposed control method, is selected to be the nominal voltage magnitude (in pu) of the grid, and its role is to keep the voltage of WFs close to nominal value when the farm does not produce power.

Converting $V_{0}$ and $\theta_{0}$ into $\mathrm{dq}$ components as $v_{\mathrm{d} 0}=$ $V_{0} \cos \left(\theta_{0}\right)$ and $v_{\mathrm{q} 0}=V_{0} \sin \left(\theta_{0}\right)$, the initial voltage reference vector $v_{\mathrm{d} 0}+j v_{\mathrm{q} 0}$ is generated to be used in inner control layer. The space vector diagram of voltage and currents of the controller is shown in Fig. 5.

\section{Inner Control Layer}

A current controller is needed, firstly, to limit the fault currents, and secondly, to provide damping to high-frequency resonances [19]. The reference values of this controller, however, should be provided using the outputs of the outer control layer. From dynamic behaviour perspective, the converter should reach a steady-state-when subjected to any change of setpoints or system disturbances - with satisfying performance and robustness. Based on this basic concept, the steady-state equation of the converter's phase reactor is used to derive the current reference vector $i_{\text {dref }}+j i_{\text {qref }}$ as

$$
i_{\text {dref }}+j i_{\mathrm{qref}}=\frac{\left(v_{\mathrm{d} 0}+j v_{\mathrm{q} 0}\right)-\left(u_{\mathrm{dref}}+j u_{\mathrm{qref}}\right)}{j \omega L_{\mathrm{c}}}
$$

where $u_{\text {dref }}+j u_{\text {qref }}$ is the reference vector of the filter-bus voltage, and is chosen as $1+j 0 \mathrm{pu}$. This selection is fair, since under the steady-state operation, the direct component of the filter-bus voltage is around $1 \mathrm{pu}$, and its quadrature component is forced to be zero by the PLL.

The proposed control method utilizes the conventional inner current control scheme [20], [21] to generate the converter's alternating voltage reference, $\mathbf{v}_{\text {ref }}$, as shown in Fig. 3. The reference vector is used in PWM to generate the driving signals for the converter switches. In per unit, the converter voltage and its reference can be expressed as $\mathbf{v}=e^{T_{\mathrm{d}} t} \mathbf{v}_{\text {ref }}$ [19], where $T_{\mathrm{d}}$ represents the total time delay of the PWM and measurement processes and is commonly assumed to be $T_{\mathrm{d}}=1.5 / f_{\mathrm{s}}$, where $f_{\mathrm{s}}$ is the switching frequency. 


\section{E. Boundaries of Control Parameters}

The lowest phase angle of the converter's voltage is selected as zero, i.e., $\theta_{\min }=0$, to prevent reverse active power flow through the WT grid-side converters (from ac to dc terminals). However, during energization and start-up condition, in which the WT may consume power from ac grid, the lowest phase angle is chosen differently. The energization process of DRconnected OWFs has been discussed in [22].

The maximum phase angle is adapted from the power-flow equation as

$$
K_{\theta} P_{\text {ref }}=\frac{\sin \left(\theta_{\text {max }}\right)}{\omega L_{\mathrm{c}}}
$$

where $K_{\theta}=1.1$, and the magnitude of converter and filter bus voltages are assumed to be $1 \mathrm{pu}$. To curb the overshoot of the active power under transients and prevent the increment of $\theta_{0}$ under faults (when $P_{\text {ref }}$ cannot be reached), there should be an upper limit to $\theta_{0}$. Such limit is indicated as $\theta_{\max }$. To determine the value of $\theta_{\max }$, it is assumed that a $10 \%$ of active power overshoot is allowed. $K_{\theta}$ (maximum power deviation coefficient) is thus selected as 1.1 , which indicates $110 \%$ of the reference power.

To limit the fault current, the reference current components in dq frame must be limited. Different limitation schemes can be used, based on system requirements. For example, in [8], the fault current control priority is given to reactive current in order to maintain the OWF's reactive power balance under disturbances. In this paper, through simulation results, it is witnessed that only by a limited amount of reactive current injection from WT converters, an acceptable fault ridethrough can be fulfilled. Therefore, the reactive current limits are adopted as $i_{\mathrm{qmax}}=-i_{\mathrm{qmin}}=0.25 \mathrm{pu}$. The active current component is limited to $i_{\mathrm{dmin}}=0$ and $i_{\mathrm{dmax}}=K_{\mathrm{idmax}} P_{\text {ref }}$, where $K_{\text {idmax }}=1.1$. Similar to the lower limit of the voltage angle, the $i_{\mathrm{dmin}}$ can posses a different value during energization and start-up processes.

\section{F. Mathematical Basis of the Proposed Control}

Active power flow through the HVdc link, shown in Fig. 1 , is determined by the difference in direct voltage at its terminals. This can be mathematically expressed as

$$
P_{\mathrm{on}}=\frac{\left(V_{\mathrm{D}, \mathrm{off}}-V_{\mathrm{D}, \mathrm{on}}\right) V_{\mathrm{D}, \mathrm{on}}}{R_{\mathrm{D}}},
$$

where $P_{\mathrm{on}}$ is the active power flowing from the $\mathrm{HVdc}$ link into the onshore $\mathrm{HVdc}$ converter, $V_{\mathrm{D}, \mathrm{on}}$ is the onshore $\mathrm{HVdc}$ terminal direct voltage, which is controlled by the onshore $\mathrm{HVdc}$ converter, $R_{\mathrm{D}}$ is the $\mathrm{HVdc}$ link resistance, and $V_{\mathrm{D}, \text { off }}$ is the offshore HVdc terminal direct voltage. The voltage at the ac side of the diode rectifiers can be calculated as

$$
V_{\mathrm{ac}, \mathrm{off}}=\frac{\pi T}{3 \sqrt{2} B} V_{\mathrm{D}, \mathrm{off}}+\frac{T X_{t}}{\sqrt{2}} I_{\mathrm{D}},
$$

where $T$ is the DR transformer turns ratio, $B$ is the number of (6-pulse) diode bridges connected in series (on their dc terminals), $X_{t}$ is the DR transformer leakage reactance, and
$I_{\mathrm{D}}$ is the direct current flowing through the HVdc link, which can be expressed as

$$
I_{\mathrm{D}}=\frac{\left(V_{\mathrm{D}, \mathrm{off}}-V_{\mathrm{D}, \mathrm{on}}\right)}{R_{\mathrm{D}}} .
$$

Substituting (4) and (5) in (3), the active power flow to the shore can be expressed as

$$
P=K_{1} V_{\text {ac,off }}+K_{2} .
$$

Assuming that the onshore $\mathrm{HVdc}$ converter keeps $V_{\mathrm{D} \text {,on }}$ at a fixed value, the constant parameters $K_{1}$ and $K_{2}$ can be obtained as

$$
K_{1}=\frac{3 \sqrt{2} B V_{\mathrm{D}, \text { on }}}{T\left(\pi R_{\mathrm{D}}+3 B X_{t}\right)}, \quad K_{2}=\frac{\pi V_{\mathrm{D}, \text { on }}^{2}}{\pi R_{\mathrm{D}}+3 B X_{t}} .
$$

As can be bserved from (7), to establish an active power flow from the DR-HVdc-connected OWF to shore, the alternating voltage magnitude of the offshore ac grid must be regulated. This regulation is made by the WT grid-side converters.

Since such OWFs would be comprised of many gridforming WTs and no high-power grid-forming $\mathrm{HVdc}$ converter, such WTs may oscillate against one another. Therefore, besides controlling the active power generation/flow, another control objective should be to ensure the stable operation of many parallel grid-forming WT converters. These two objectives must be fulfilled by controlling the angle and magnitude of the alternating voltage at terminals of the WT grid-side converters. If, by any means, such voltage magnitude can be changed synchronously, the risk of oscillations (especially reactive power oscillations) among WT converters decreases. In order to do this, voltage magnitude control based on the frequency deviation is proposed. Since the frequency is a universal parameter, its deviation is seen equally by all converters, and as a result, their voltage magnitude can be changed at the same time.

The frequency change, however, must be initiated by the active power control loop. Since frequency is the derivative of the voltage phase angle, adapting the classical power-angle control satisfies the required frequency changes. To mathematically present the control mechanism, explained above, it is assumed that any power mismatch is translated into a phase angle deviation of the WT converter's alternating voltage through a PI controller, as

$$
\Delta \theta_{0}=-\mathrm{PI}_{\mathrm{p}}(s) \Delta P
$$

The active power equation of a WT converter is stated as

$$
P=\frac{V U}{X_{\mathrm{c}}} \sin \left(\theta_{\mathrm{v}}-\theta_{\mathrm{u}}\right)
$$

where $X_{\mathrm{c}}=\omega L_{\mathrm{c}}$, and $V$ and $U$ are the voltage magnitude of converter voltage and filter bus voltage, respectively. The filter reactance $L_{\mathrm{c}}$ is normally so small that the phase angle difference at its terminals is fairly small, so that $\sin \left(\theta_{\mathrm{v}}-\theta_{\mathrm{u}}\right) \approx$ $\theta_{\mathrm{v}}-\theta_{\mathrm{u}}$. With such assumption, the phase angle deviation of the filter bus voltage can be obtained from (9) as

$$
\Delta \theta_{\mathrm{u}}=\Delta \theta_{\mathrm{v}}-\frac{X_{\mathrm{c}}}{V^{0} U^{0}} \Delta P
$$


where $V^{0}$ and $U^{0}$ are the corresponding steady-state values, and $\Delta \theta_{\mathrm{v}}=\Delta \theta_{0}$. The frequency deviation is estimated by a PLL that is locked to the filter bus voltage. The input to the corresponding PI regulator in the PLL is the q-axis component of the alternating voltage in the corresponding rotating (dq) reference frame, which is calculated by means of the Park transformation,

$$
u_{\mathrm{q}}=U \sin \left(\theta_{\mathrm{u}}-\theta_{\mathrm{s}}\right)
$$

where $\theta_{\mathrm{s}}(t)$ is the transformation/reference angle, generated by the PLL. The angles in (11) are defined as $\theta_{\mathrm{u}}(t)=$ $\omega_{0} t+\Delta \theta_{\mathrm{u}}, \theta_{\mathrm{s}}(t)=\omega_{0} t+\Delta \theta_{\mathrm{s}}$, where $\omega_{0}$ is the rated angular speed/frequency. Recalling that the PLL is locked to the filter bus voltage, it can be assumed that that the difference between $\theta_{\mathrm{u}}(t)$ and $\theta_{\mathrm{s}}(t)$ is so small that leads to $\sin \left(\theta_{\mathrm{u}}-\theta_{\mathrm{s}}\right) \approx \theta_{\mathrm{u}}(t)-\theta_{\mathrm{s}}(t)=\Delta \theta_{\mathrm{u}}-\Delta \theta_{\mathrm{s}}$. Therefore, considering (10) and neglecting voltage magnitude change, i.e., $U \approx U^{0}, u_{\mathrm{q}}$ in (11) can be expressed as

$$
u_{\mathrm{q}}=U^{0} \Delta \theta_{0}-\frac{X_{\mathrm{c}}}{V^{0}} \Delta P-U^{0} \Delta \theta_{\mathrm{s}} .
$$

The frequency deviation $\Delta \omega$ is estimated by the PLL via the PI regulator as $\Delta \omega=\mathrm{PI}_{\mathrm{pll}}(s) u_{\mathrm{q}}$. The reference angle deviation $\Delta \theta_{\mathrm{s}}$ is also generated withing the PLL by integration from the frequency deviation, i.e., $\Delta \theta_{\mathrm{s}}=\Delta \omega / \mathrm{s}$. Thus,

$$
\Delta \omega=\mathrm{PI}_{\mathrm{pll}}(s)\left(U^{0} \Delta \theta_{0}-\frac{X_{\mathrm{c}}}{V^{0}} \Delta P-\frac{U^{0}}{s} \Delta \omega\right),
$$

which implies that the frequency deviation exists as long as there is an active power mismatch in the control system. On the other hand, the active power can be controlled by manipulating the alternating voltage magnitude, as shown in (9). Therefore, from (9) and (13) it is proposed to regulate the voltage magnitude based on the frequency deviation, as

$$
\Delta V_{0}=\mathrm{PI}_{\mathrm{frq}}(s) \Delta \omega
$$

Based on (9), (13) and (14) the block diagram shown in Fig. 6 is obtained. The current control loop has been assumed to have a closed-loop bandwidth of $\alpha_{c}$. It is also assumed that the impact of the offshore array cables on voltage magnitude is negligible. Therefore, the converter voltage $V$ and the offshore substation voltage $V_{\text {ac,off }}(4)$ have the same magnitude in per unit.

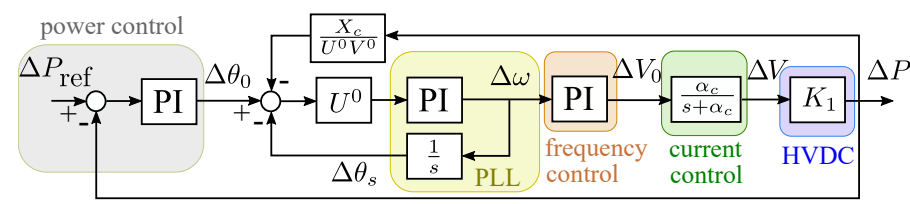

Fig. 6. Block diagram of active power control in a DR-HVdc connected OWF with the proposed control.

Fig. 6 shows how employing frequency control together with conventional power-angle control facilitates a change in voltage magnitude, which in turn facilitates the desired active power flow in a DR-connected OWF.

\section{G. Comparison with Other Control Schemes}

In the previously proposed grid-forming control methods for DR-connected OWFs, described in [3] and [8], the active and reactive power, as well as frequency, are controlled by regulating the filter-bus voltage $\mathbf{u}$. In other words, the outputs of their outer control loop are the reference values fed to the filter-bus voltage controller. Differently, in the proposed control method in this paper, outputs of the outer control loop are the reference values of the converter voltage $\mathbf{v}$. Therefore, there is no need for additional regulators to control the filterbus voltage, resulting in a simpler control system with loworder dynamics.

Comparing to the control scheme in [3], the proposed control system is centralized and uses only local measurements, and thereby, does not require high-speed communication links. Moreover, unlike that in [3], none of the proposed controller settings (gains) directly depends on system component parameters, e.g., capacitance of capacitor bank at the offshore station.

The offshore frequency is proportionally controlled in [3] and [8], while in the proposed control, it is controlled by a PI regulator, which eliminates the frequency error under steadystate operation.

The current control and PLL structure employed in this paper are the same as those used in [8] and [12]; however, with different ways of current reference generation, implemented in the outre control layer.

\section{Simulations}

Simulations of the proposed control method are conducted in PSCAD, and their results presented in this section. The OWF, whose schematic diagram is illustrated in Fig. 1, is used for simulations. To capture a thorough insight into the capabilities of the proposed control approach its reactions and operabilities under different operational scenarios are evaluated. The chosen scenarios are expected to create more severe and challenging conditions for the operation and control of a DR-connected OWF. These scenarios include three-phase short-circuit in the offshore ac grid, active power change of the WTs, disturbance in reactive power control of the farm, and wind turbines outage.

All control settings and system parameters used for simulations are presented in the Appendix. For the sake of visibility in simulation results, shown in figures of this section, the WTs' active power setpoints are selected to be slightly different from each other. The voltage $V^{*}$ and reactive power setpoint of all WTs are respectively selected to be 1 and $0 \mathrm{pu}$. The base values of power and ac voltage for each WT converter are $8 \mathrm{MVA}$ and $0.69 \mathrm{kV}$ (the rated voltage of converters), respectively.

\section{A. Three-phase Short Circuit at $66 \mathrm{kV} \mathrm{Bus}$}

To assess the fault ride-through capability of the proposed control, a $100 \mathrm{~ms}$ three-phase solid short-circuit is applied on $66 \mathrm{kV}$ bus (collection bus) of the offshore substation. Figures 7-9 show the results of this simulation. The dc-link voltage of both ends of the HVdc link, as well as the instantaneous 


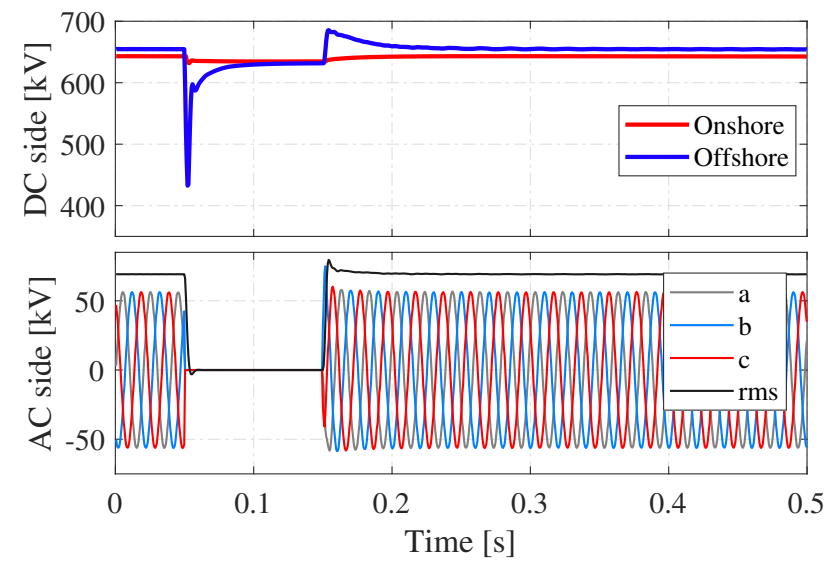

Fig. 7. Direct voltage of HVDC link (top), and alternating voltage at DR platform (bottom) under short circuit at $66 \mathrm{kV}$ bus.

and rms value of the offshore alternating voltage are illustrated in Fig. 7, the WTs' active and reactive power in Fig. 8, and converter currents in dq frame in Fig. 9.

The active and reactive power recovery after the fault is satisfactorily fast (compared with similar studies implemented in [5] and [12]), with acceptable dynamics, i.e., without experiencing significant over-shoots or undamped oscillations. After such a rigorous incident, no reactive power interaction (ping-ponging from WT to another) among the WTs. The phenomenon can be the case between grid-forming converters, without a strong grid supporting the reactive power balance. The reason for such adequate performance is that the control system of each WT converter uses the frequency deviation to adjust the converter voltage magnitude. Since the frequency deviation is a universal parameter, all WT converters measure the same variation and adjust their voltage magnitude with the same value, which results in an identical reactive power response. However, not all converters supply the same amount of reactive power under the fault, shown in Fig. 8, because the distance of WTs to the fault location is different, and they experience difference impedance under the fault. The current magnitude of WTs is shown in Fig. 9, indicating that the control system is capable of limiting the fault current. However, it should be noted that the current control bandwidth is selected as $400 \mathrm{~Hz}$, which is almost twice that of gridfollowing converters [19]. This bandwidth requires a faster switching frequency, i.e., around $4 \mathrm{kHz}$ for $50 \mathrm{~Hz}$ ac grid, which is feasible with current IGBT (insulated-gate bipolar transistor) switching technology.

With lower current control bandwidth, i.e., $200 \mathrm{~Hz}$, some spikes on converter currents are observed under such a shortcircuit event.

It is noteworthy that a severe short circuit at the HVdc link has the same impact on the offshore ac grid as the three-phase short circuit at $66 \mathrm{kV}$ bus.

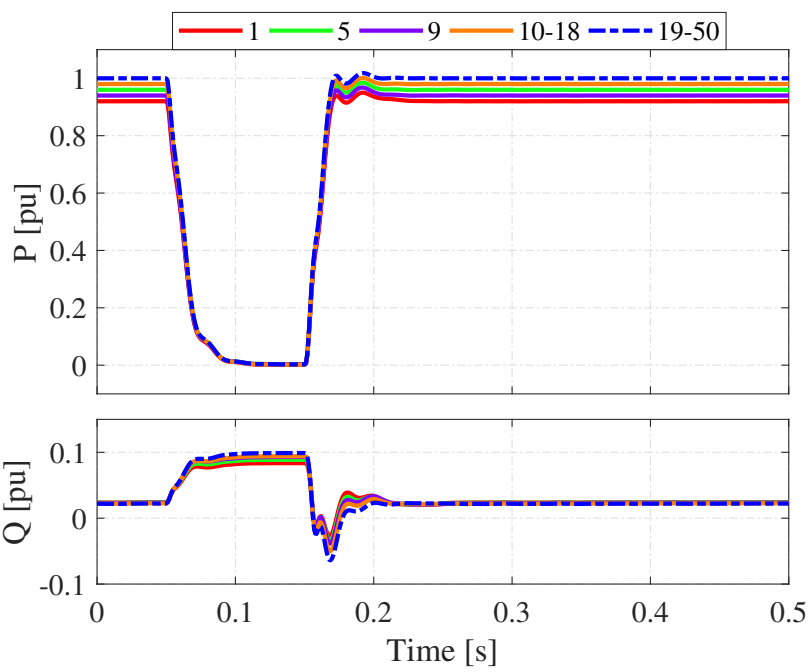

Fig. 8. Active (top) and reactive (bottom) power of WTs under short circuit at $66 \mathrm{kV}$ bus.

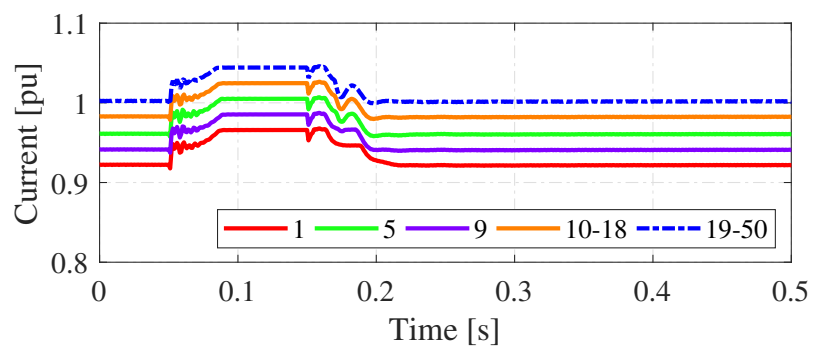

Fig. 9. Current magnitude of converters under short circuit at $66 \mathrm{kV}$ bus.

\section{B. Changing the Active Power Production}

A wind farm's active power can be changed due to the variations of wind speed, or a request of power-change from system operators. However, each WT must be able to regulate its active power production independently, regardless of the power production of other WTs. To show the capability of independent active power change, with the proposed control approach, step-changes are applied to WTs' active power setpoints at different times. Generally, there are active power ramp-rate limits, restricting the speed of change of the WTs' active power [23]. In this simulation, the active power ramprate has been chosen intentionally high, i.e., $4 \mathrm{pu} / \mathrm{sec}$, to see the performance (reference tracking) of the proposed controller.

Under this simulation, the reactive power compensation in DR-platform is kept constant, and WTs are assumed to be responsible for balancing the reactive power in the offshore network. It is also assumed that there are enough aerodynamic power so that the WTs can operate with their nominal power after increasing their setpoints.

The simulation results are presented in Figs. 10 and 11. It is shown in Fig. 11 that how active power of WTs can be changed independently without affecting other WTs production. However, the reactive power of all WTs are changed almost equally to compensate the power factor of the DR converters. The 


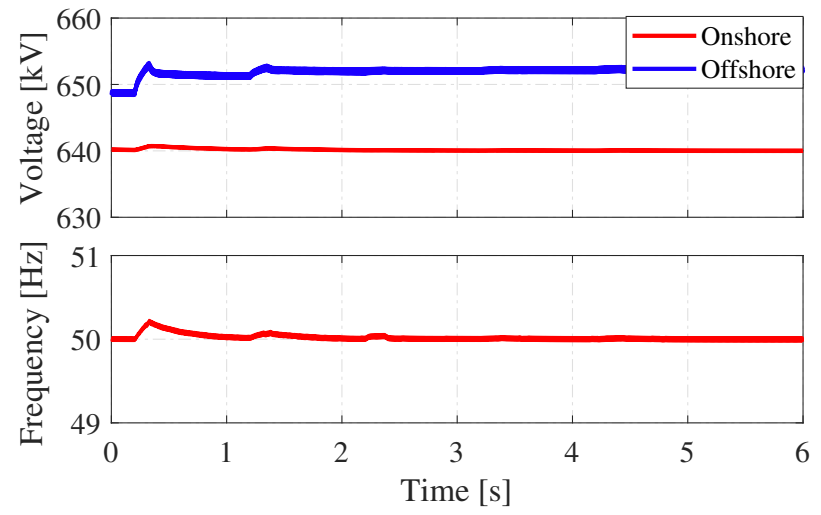

Fig. 10. Direct voltage of HVDC link (top), and offshore frequency (bottom) under step changes applied to WTs active power.
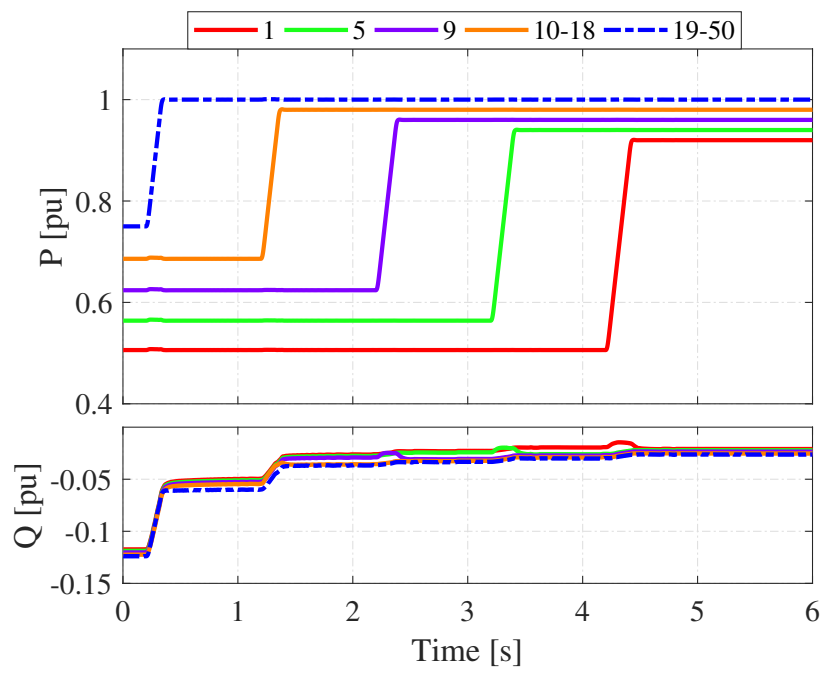

Fig. 11. Active (top) and reactive (bottom) under step changes applied to WTs active power.

reactive power change is more significant when most of WTs (WTs 10-50) undergo an active power change. This is because the power factor compensation of DRs requires more reactive power.

The offshore frequency, shown in Fig. 10, experience larger change when the active power change is significant. However, it returns back to its nominal value since there is a PI controller in the frequency control loop. The bigger the active power change, the larger variation of the offshore frequency. For instance, when WTs 19-50 change their active power the offshore frequency undergoes a bigger change.

\section{Outage of Reactive Power Compensator in DR Platform}

In a DR-connected OWF, the reactive power flow is not independent of active power flow. Higher active power flow through DR converters requires higher reactive power flow as well. However, to optimize the OWF operation in terms of loss reduction and WTs loading, the reactive power required by DR converters is supplied locally on the offshore platform
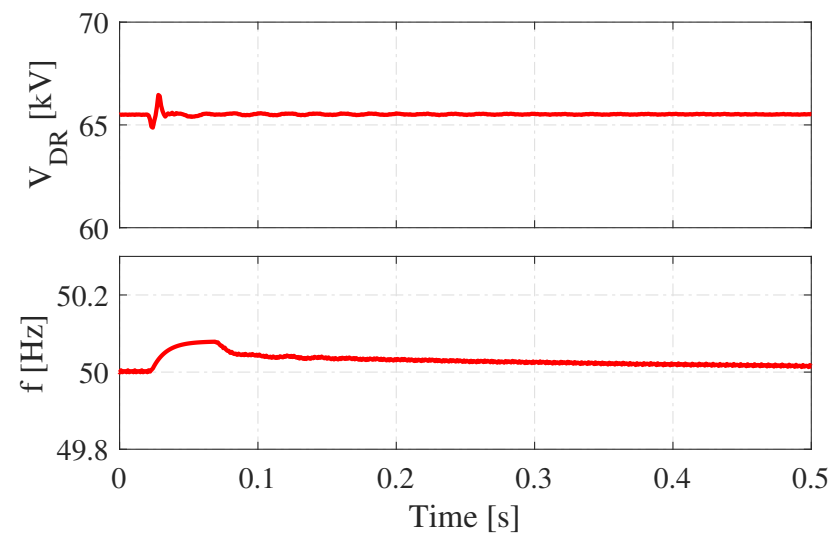

Fig. 12. The rms voltage of DR platform (top) and offshore frequency (bottom) when one of the reactive power compensators on the DR platform trips.

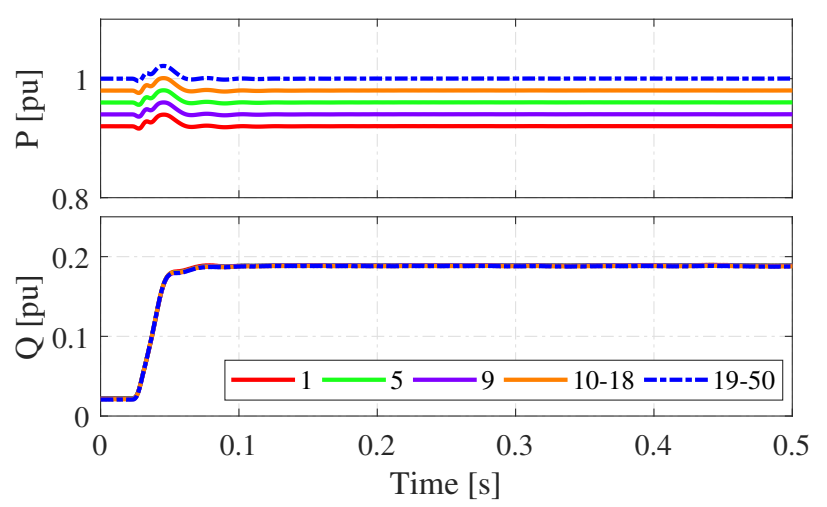

Fig. 13. Active (top) and reactive (bottom) when one of the reactive power compensators on the DR platform trips.

to prevent substantial current flowing through the array cables as well as WTs' equipment.

To show the WTs' reaction against reactive power disturbance, and prove that WTs are able to continue operating and producing the desired power under such contingency, it is assumed that one of the passive filters (which is also supply capacitive reactive power) on the DR platform trips. The tripped filter compensates 65 Mvar capacitive reactive power. It is expected that the WTs immediately react to the reactive power deficit and reestablish the balance without imposing a significant disturbance on the active power production. Simulation results for this scenario are shown in Figs. 12 and 13. The WTs react almost immediately to the perturbance and increase their reactive power, as shown in Fig. 13. The active power production of the WTs, as well as the offshore voltage, are not impacted significantly. However, the offshore frequency, shown in Fig. 12, has been slightly changed, but it recovers within a reasonably short time.

\section{Wind Turbines Outage}

Another possible scenario that can happen in an OWF, is the outage of WTs. Should for any reason some of WTs trip, 


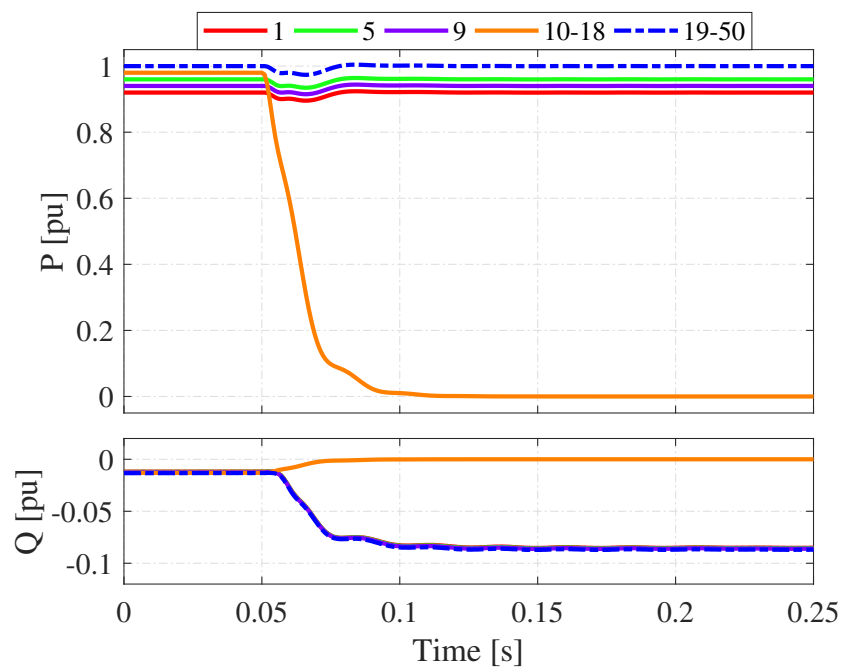

Fig. 14. Active (top) and reactive (bottom) when a string of WTs trips.
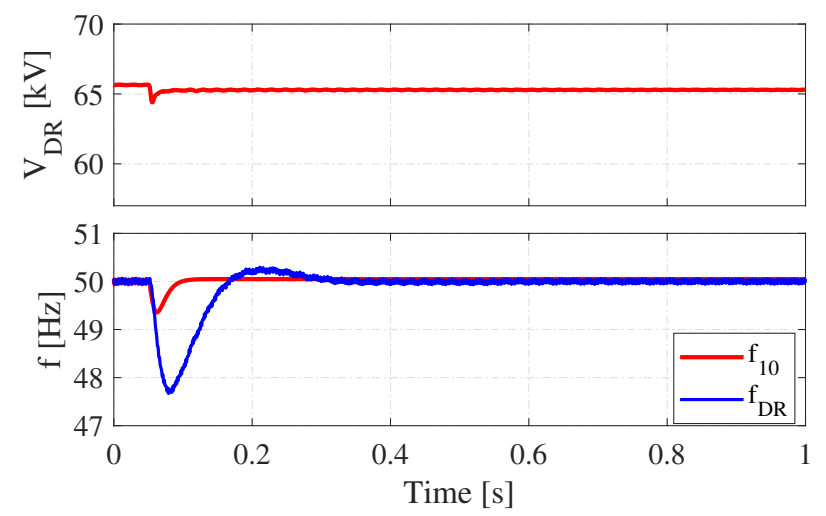

Fig. 15. The offshore alternating voltage (top) and frequencies of DR platform and the lumped model of WTs 10-18 (bottom).

the rest must be able to continue operating and produce their reference active power. To analyze this scenario, it is assumed that the aggregated string including 9 WTs (10-18) is suddenly disconnected from the DR platform. The reaction of other WTs in terms of active power production, maintaining the offshore frequency, and establishing the reactive power balance in the farm are observed from the simulation results, shown in Fig. 14 and 15. With a negligible transient, as shown in Fig. 14, the active power production of the remaining WTs are not affected. However, to maintain the reactive power balance in the farm, the WTs immediately react with modifying their reactive power. The alternating voltage and offshore frequency are shown in Fig. 15. The offshore alternating voltage, shown as $V_{\mathrm{DR}}$ in Fig. 15, drops after the incident since the DR conducts less active power comparing to pre-event. The frequencies of offshore grid and the tripped WTs, shown in 15, are within an acceptable limits, experiencing insignificant transients. The $\mathrm{dq}$ components of the current of the tripped WTs are shown in Fig. 16.

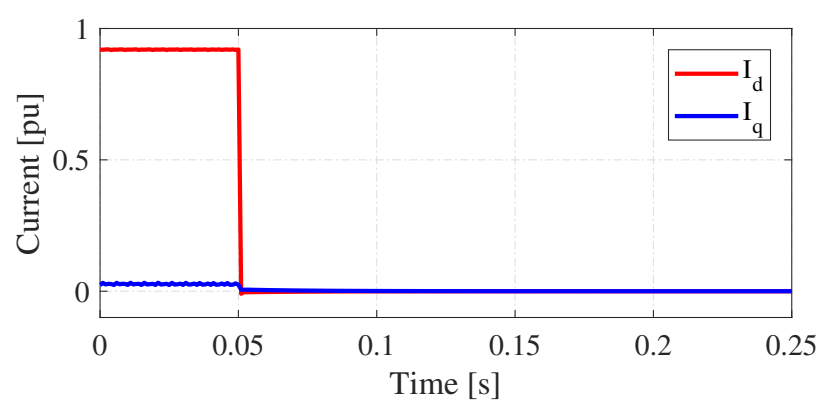

Fig. 16. Inner current of the lumped model of WTs 10-18.

\section{CONCLUSiOns}

A grid forming control scheme was proposed for the wind turbine converters in diode rectifier (DR)-connected offshore wind farms. The controller initiates the active power control by regulating the converter's voltage angle, which leads to a frequency deviation. This deviation is used to regulate the alternating voltage magnitude of the converter, and consequently, the magnitude of DRs' ac-side voltage, which results in power-flow control through the DRs. The frequency control of the wind farm is established using a PI regulator for each of the wind turbines. The proposed control approach has a simpler structure with less dynamics compared with other controllers with the same application. By means of simulation results, it was shown that the proposed controller can limit fault current, independently (from other wind turbines) change the converter's active power, satisfactorily react to reactive power disturbances of the farms, and continue operating under severe case of contingencies.

\section{APPENDIX}

The controllers' settings and system parameters used for simulations are presented in this section. The time constant of active and reactive power measurements is $10 \mathrm{~ms}$. The same time constant is applied for measuring alternating voltage magnitudes. Control settings used for WTs' grid-side converters are given in Table I. All parameters shown in this table are based on per-unitized values.

TABLE I

WTS GRID-SIDE CONVERTER CONTROL PARAMETERS

\begin{tabular}{lll}
\hline Active power controller & $k_{\mathrm{p}}=0.05$ & $k_{\mathrm{i}}=6.66$ \\
Frequency controller & $k_{\mathrm{p}}=62.8$ & $k_{\mathrm{i}}=157$ \\
Reactive power controller & $k_{\mathrm{Q}}=0.3$ & \\
Converter current controller & $k_{\mathrm{p}}=1.5$ & $k_{\mathrm{i}}=33.3$ \\
Phase-locked loop (PLL) & $k_{\mathrm{p}}=0.11$ & $k_{\mathrm{i}}=0.01$ \\
Maximum current coefficient & $K_{\mathrm{imax}}=1.1$ & \\
\hline
\end{tabular}

A pair of export cables is used with frequency dependent (phase) model options in PSCAD. The length of the cables is $200 \mathrm{~km}$ with the core resistance of $1.72 \times 10^{-8} \Omega \mathrm{m}$. The dimensions of one of the cables is shown in Fig. 17.

A lumped T-model is used for array cables with inductance of $4.0 \times 10^{-5} \mathrm{H} / \mathrm{km}$, resistance of $0.01 \Omega / \mathrm{km}$, and capacitance of $0.0304 \mu \mathrm{F} / \mathrm{m}$. The distance between every two WTs 


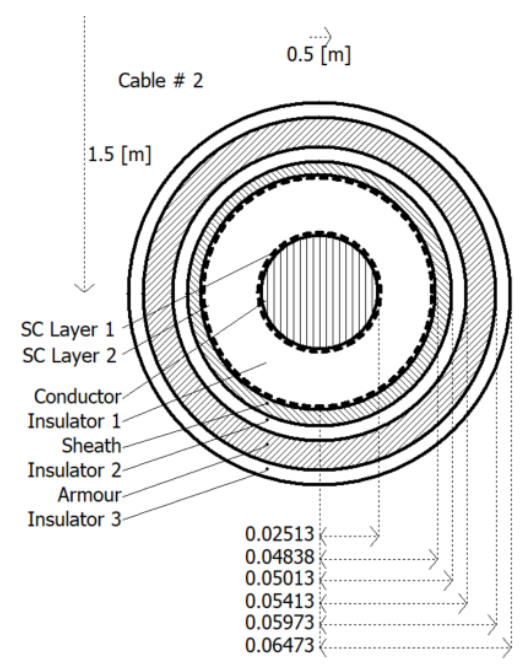

Fig. 17. Export cable dimensions and positions (horizontally with respect to the fist cable, and vertically with respect to the sea-bed) in meter.

in strings is $1 \mathrm{~km}$, and distance from offshore substation to the first WTs in each string is $2 \mathrm{~km}$.

TABLE II

CONTROLLER AND COMPONENT PARAMETERS OF ONSHORE MMC

\begin{tabular}{lll}
\hline Direct voltage control & $k_{\mathrm{p}}=100$ & $k_{\mathrm{i}}=330$ \\
Reactive power control & $k_{\mathrm{p}}=12$ & $k_{\mathrm{i}}=100$ \\
Inner current control & $k_{\mathrm{p}}=2$ & $k_{\mathrm{i}}=50$ \\
MMC submodule & 200 per arm & $C=10 \mathrm{mF}$ \\
Arm reactor & $R=0.006 \Omega$ & $L=60 \mathrm{mH}$ \\
\hline
\end{tabular}

TABLE III

WTS COMPONENTS' SPECIFICATIONS

\begin{tabular}{lll}
\hline Base values & $S=8 \mathrm{MVA}$ & $V=0.69 \mathrm{kV}$ \\
Phase reactor & $L_{\mathrm{c}}=0.047 \mathrm{mH}(0.25 \mathrm{pu})$ & \\
Filter-bus capacitor & $C_{\mathrm{f}}=2671 \mu \mathrm{F}$ & \\
WT transformer & $S_{\mathrm{n}}=8.8 \mathrm{MVA}$ & $X_{\mathrm{l}}=0.1 \mathrm{pu}$ \\
\hline
\end{tabular}

The specifications of all of the components consisting passive filter, reactive power bank, transformer, and DR converters, used in this paper, are given in [14] and [15].

The DR platform shown in Fig. 1 consists the power components shown in Fig. 18. The platform consists of passive filters, two three-winding transformers, four six-pulse diode rectifiers and two dc reactors.

\section{REFERENCES}

[1] WindEurope, "Offshore Wind in Europe - Key trends and statistics 2018," Brussels, Belgium, Report, Feb. 2019. [Online]. Available: https : // windeurope . org / members - area / statistics / offshore - wind - in - europe 2018/.

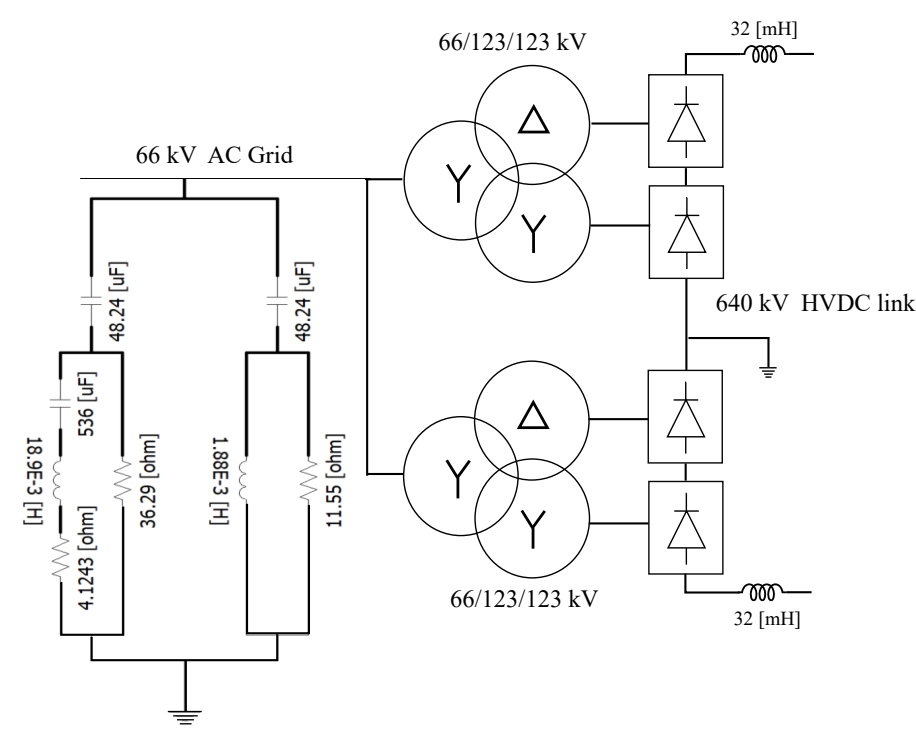

Fig. 18. Detailed presentation of the DR platform.

[2] CIGRÉ Working Group B4.55, "HVDC Connection of Offshore Wind Power Plants," Paris, France, Technical Brochure 619, May 2015. [Online]. Available: https://ecigre.org/publication/619-hvdc-connection-of-offshorewind-power-plants.

[3] R. M. Blasco-Giménez, S. C. Añó-Villalba, J. Rodríguez-D'Derlée, F. Morant-Anglada, and S. I. Bernal-Pérez, "Distributed Voltage and Frequency Control of Offshore Wind Farms Connected With a DiodeBased HVdc Link," IEEE Transactions on Power Electronics, vol. 25, no. 12, pp. 3095-3105, Dec. 2010.

[4] R. M. Blasco-Giménez, S. C. Añó-Villalba, J. Rodríguez-D’Derlée, S. I. Bernal-Pérez, and F. MorantAnglada, "Diode-Based HVdc Link for the Connection of Large Offshore Wind Farms," IEEE Transactions on Energy Conversion, vol. 26, no. 2, pp. 615-626, Mar. 2011.

[5] S. I. Bernal-Pérez, S. C. Añó-Villalba, R. M. BlascoGiménez, and J. Rodríguez-D’Derlée, "Efficiency and Fault Ride-Through Performance of a Diode-Rectifierand VSC-Inverter-Based HVDC Link for Offshore Wind Farms," IEEE Transactions on Industrial Electronics, vol. 60, no. 6, pp. 2401-2409, Jun. 2013.

[6] T. Christ, S. Seman, and R. Zurowski, "Investigation of DC Converter Nonlinear Interaction with Offshore Wind Power Park System," in Proceedings of the 2015 EWEA Offshore Conference, Copenhagen, Denmark, 10th-12th Mar. 2015.

[7] P. Menke, R. Zurowski, T. Christ, S. Seman, G. Giering, T. Hammer, W. Zink, F. Hacker, D. Imamovic, J. Thisted, P. Brogan, and N. Goldenbaum, "2nd Generation DC Grid Access for Large Scale Offshore Wind Farms," in Proceedings of the 14th Wind Integration Workshop, Brussels, Belgium, 20th-22nd Oct. 2015.

[8] L. Yu, R. Li, and L. Xu, "Distributed PLL-Based Control of Offshore Wind Turbines Connected With DiodeRectifier-Based HVDC Systems," IEEE Transactions on 
Power Delivery, vol. 33, no. 3, pp. 1328-1336, Jun. 2018.

[9] O. Saborı-Romano, A. Bidadfar, J. N. Sakamuri, Ö. Göksu, and N. A. Cutululis, "Novel energisation method for offshore wind farms connected to hvdc via diode rectifiers," in IECON 2019-45th Annual Conference of the IEEE Industrial Electronics Society, IEEE, vol. 1, 2019, pp. 4837-4841.

[10] R. M. Blasco-Giménez, N. Aparicio-Marín, S. C. AñóVillalba, and S. I. Bernal-Pérez, "LCC-HVDC Connection of Offshore Wind Farms With Reduced Filter Banks," IEEE Transactions on Industrial Electronics, vol. 60, no. 6, pp. 2372-2380, Jun. 2013.

[11] C. Prignitz, H. G. Eckel, S. Achenbach, F. Augsburger, and A. Schön, "FixReF: A control strategy for offshore wind farms with different wind turbine types and diode rectifier HVDC transmission," in Proceedings of the IEEE 7th International Symposium on Power Electronics for Distributed Generation Systems (PEDG 2016), Vancouver, BC, Canada, 27th-30th Jun. 2016.

[12] R. Li, L. Yu, and L. Xu, "Offshore AC Fault Protection of Diode Rectifier Unit-Based HVdc System for Wind Energy Transmission," IEEE Transactions on Industrial Electronics, vol. 66, no. 7, pp. 5289-5299, Jul. 2019.

[13] O. Saborío-Romano, A. Bidadfar, J. N. Sakamuri, Ö. Göksu, and N. A. Cutululis, "Primary Frequency Response from Offshore Wind Farms Connected to HVdc via Diode Rectifiers," in Proceedings of the 13th IEEE PES PowerTech Conference, Milan, Italy, 23rd-27th Jun. 2019.

[14] PROMOTioN, "Deliverable 3.1: Detailed functional requirements to WPPs," Project Deliverable, Dec. 2016. [Online]. Available: https://www.promotion-offshore. net/fileadmin/PDFs/D3.1_PROMOTioN_Deliverable_3. 1_Detailed_functional_requirements_to_WPPs.pdf.

[15] _- "Deliverable 3.2: Specifications of the control strategies and the simulation test cases," Project Deliverable, Mar. 2017. [Online]. Available: https://www. promotion - offshore . net / fileadmin / PDFs / D3 . 2 _ Specifications_Control_strategies_and_simulation_test_ cases.pdf.

[16] E. Muljadi, S. Pasupulati, A. Ellis, and D. Kosterov, "Method of Equivalencing for a Large Wind Power Plant with Multiple Turbine Representation," in Proceedings of the IEEE PES 2008 General Meeting, Pittsburgh, PA, United States, 20th-24th Jul. 2008.

[17] B.-T. Ooi, and X. Wang, "Voltage Angle Lock Loop Control of the Boost Type PWM Converter for HVDC Application," IEEE Transactions on Power Electronics, vol. 5, no. 2, pp. 229-235, Apr. 1990.

[18] J. Svensson, "Voltage Angle Control of a Voltage Source Inverter - Application to a Grid-Connected Wind Turbine," in Proceedings of the 6th European Conference on Power Electronics and Applications (EPE '95), vol. 3, Sevilla, Spain, pp. 539-544.

[19] L. Harnefors, M. Bongiorno, and S. Lundberg, "InputAdmittance Calculation and Shaping for Controlled Voltage-Source Converters," IEEE Transactions on In- dustrial Electronics, vol. 54, no. 6, pp. 3323-3334, Dec. 2007.

[20] J.-W. Choi, and S.-K. Sul, "Fast Current Controller in Three-Phase AC/DC Boost Converter Using $d-q$ Axis Crosscoupling," IEEE Transactions on Power Electronics, vol. 13, no. 1, pp. 179-185, Jan. 1998.

[21] M. P. Kaźmierkowski, and L. Malesani, "Current Control Techniques for Three-Phase Voltage-Source PWM Converters: A Survey," IEEE Transactions on Industrial Electronics, vol. 45, no. 5, pp. 691-703, Oct. 1998.

[22] O. Saborío-Romano, A. Bidadfar, J. N. Sakamuri, Ö. Göksu, and N. A. Cutululis, "Novel Energisation Method for Offshore Wind Farms Connected to HVdc via Diode Rectifiers," in Proceedings of the 45th IEEE IES Annual Conference (IECON 2019), Lisbon, Portugal, 14th-17th Oct. 2019, pp. 4837-4841.

[23] L. Zeni, "Power system integration of VSC-HVDC connected wind power plants: Control principles, power system services, clustering of wind power plants," $\mathrm{PhD}$ thesis, Technical University of Denmark, Roskilde, Denmark, Mar. 2015.

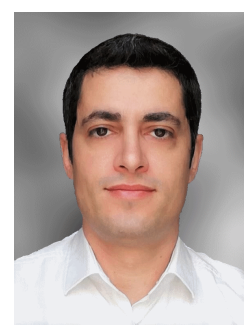

Ali Bidadfar (M'14) worked as a power system researcher at KTH Royal Institute of Technology from 2013 to 2016. He has been a $\mathrm{PhD}$ researcher at the Technical University of Denmark since 2016. During his $\mathrm{PhD}$, he has focused on frequency support provision from offshore HVdc grids. In August 2019, he joined Ørsted, Denmark, as a power system engineer. His research interests include HVdc control and operation, offshore wind generation and transmission technologies, control and stability of power systems.

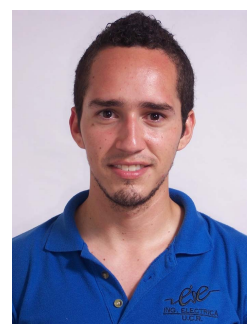

Oscar Saborío-Romano (S'12) received the BSc (Hons) degree in Electrical Engineering from the University of Costa Rica in 2013. In 2015, he received the MSc degrees in Electrical Engineering and Wind Energy from Delft University of Technology and the Norwegian University of Science and Technology, respectively. He joined the Department of Wind Energy at the Technical University of Denmark in 2016, where he has pursued a PhD. His research interests include power system control and stability, integration of renewable energy sources, modelling and control of wind power, HVdc transmission, and microgrids.

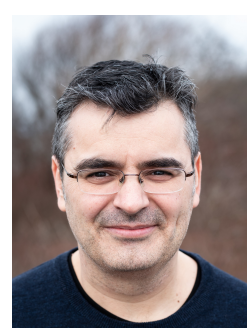

Nicolaos A. Cutululis (SM'18) received the MSc and $\mathrm{PhD}$ degrees, both in Automatic Control, in 1998 and 2005, respectively. Currently, he is a professor at the Department of Wind Energy, Technical University of Denmark. His main research interests are integration of wind power, with a special focus on offshore wind power, and grids. 


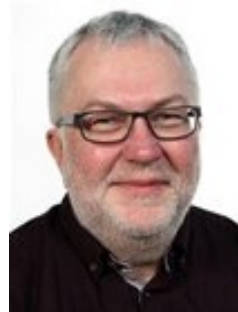

Poul E. Sørensen (SM'07) is professor in wind power integration and control in the Department of Wind Energy at the Technical University of Denmark. He was born in 1958 and received M.Sc. degree in electrical engineering from DTU in 1987. $\mathrm{He}$ is convener of IEC 61400-27 electrical simulation models for wind power generation. $\mathrm{He}$ is also principal investigator and work package leader in a number of research projects and has supervised $20 \mathrm{PhD}$ students and 30 Master thesis. He has been senior member since 2007 . 